\title{
Inhibitory roles of miR-9 on papillary thyroid cancer through targeting BRAF
}

\author{
YI GU $^{1}$, NAN YANG ${ }^{2}$, LEPING YIN ${ }^{1}, \mathrm{CHAO} \mathrm{FENG}^{1}$ and TONG LIU $^{1}$ \\ ${ }^{1}$ Sichuan Academy of Medical Sciences, Sichuan Provincial People's Hospital, Chengdu, Sichuan 610072; \\ ${ }^{2}$ College of Pharmacy, Chengdu University of Traditional Chinese Medicine, Chengdu, Sichuan 611137, P.R. China
}

Received December 8, 2016; Accepted July 24, 2017

DOI: $10.3892 / \mathrm{mmr} .2018 .9010$

\begin{abstract}
MicroRNA-9 (miR-9) is reported to be underexpressed in papillary thyroid carcinoma (PTC) tissues; however, the molecular mechanisms underlying the implication of miR-9 in PTC have yet to be elucidated. The present study aimed to explore the potential roles of miR-9 in PTC. PTC tissue samples and paired non-cancerous adjacent tissues were collected from 60 patients with PTC. The human TPC-1 thyroid gland papillary carcinoma cell line was used to investigate the molecular mechanisms underlying the roles of miR-9 in PTC. The levels of miR-9 and its downstream target gene BRAF were detected through reverse transcription-quantitative polymerase chain reaction. MTT assay and flow cytometry were performed to evaluate cell viability and apoptosis, respectively. A mouse xenograft tumor model was established to observe the effects of miR-9 on thyroid gland tumorigenesis in vivo. The present study revealed that the expression of miR-9 was significantly reduced in PTC tissues compared with paired normal tissues. In addition, miR-9 upregulation suppressed the expression of BRAF in TPC-1 cells in vitro. Luciferase reporter assay demonstrated that BRAF may be a direct target gene of miR-9 in TPC-1 cells. In addition, following transfection with miR-9 mimics, the viability of TPC-1 cells was suppressed and their apoptosis was enhanced; conversely, transfection with miR-9 inhibitor exerted the opposite effects in vitro. miR-9 overexpression or downregulation also affected in vivo PTC tumorigenesis in athymic mice. The present findings suggested that miR-9 may suppress the viability of PTC cells and inhibit tumor growth through directly targeting the expression of BRAF in PTC.
\end{abstract}

Correspondence to: Dr Yi Gu, Sichuan Academy of Medical Sciences, Sichuan Provincial People's Hospital, 32 West Second Section First Ring Road, Chengdu, Sichuan 610072, P.R. China E-mail: guyi516@126.com

Key words: miR-9, BRAF, papillary thyroid carcinoma, viability, apoptosis, tumorigenesis

\section{Introduction}

Thyroid cancer is one of the most frequent types of endocrine neoplasms worldwide, with $\sim 300,000$ new cases occurring every year $(1,2)$. Due to several environmental and socioeconomic factors, the occurrence rate of thyroid cancer is more increased among rural populations (3). Thyroid cancer has been identified as one of the most common types of malignancy among Asian population in 2015 (4). Based on the degree of cell differentiation, thyroid cancer can be classified into several types, including papillary thyroid carcinoma (PTC), medullary thyroid carcinoma (MTC) and follicular thyroid carcinoma (5). PTC accounts for the majority of thyroid carcinomas, and is responsible for $\sim 80 \%$ of global thyroid cancer cases $(6,7)$.

Although the 5-year survival rate of PTC exceeds $90 \%$, the occurrence of lymph node metastasis is frequent and the recurrence risk remains high $(8,9)$. The most common therapeutic strategy used for PTC treatment is thyroidectomy, which is featured by a high success rate of $\sim 85 \%(10,11)$. However, previous studies have reported that $20 \%$ of patients with PTC who underwent thyroidectomy exhibited regional recurrence during a mean follow-up of $<5$ years $(10,12)$. In addition, thyroidectomy is characterized by various limitations, and the application of surgery for lymph node excision remains controversial $(13,14)$. Therefore, investigation of the cellular and molecular mechanisms involved in PTC is essential for the development of more effective therapeutic strategies to prevent the recurrence in patients.

MicroRNAs (miRNAs) are a class of small non-coding RNA molecules with a length of 20-22 nucleotides, which regulate gene expression at the post-transcriptional stage and participate in numerous cellular processes, including cell proliferation, differentiation and apoptosis $(15,16)$. miRNAs have been suggested to serve an important role in the development of PTC (17). For example, let-7 is associated with PTC, through the regulation of high-mobility group AT-hook 2 (HMGA2) and solute carrier family 5 member 5 (SLC5A5) expression (18). miR-146 has been reported to suppress the expression of the retinoic acid receptor $\beta$ in PTC, thus attenuating the efficiency of retinoic acid and radioactive iodine treatment, which suggests that the deregulation of miRNA may also influence the therapeutic outcome of PTC treatment (19). Previous studies have reported that the metastasis and proliferation of thyroid carcinoma cells could be regulated by several 
miRNAs (20), including miR-146b (21), miR-451a (22) and miR-205 (23). Sondermann et al (24) suggested that miR-9 may have potential prognostic value for predicting the recurrence of PTC, as miR-9 expression in patients with non-recurrent PTC was significantly higher compared with patients with recurrent PTC. Gundara et al (25) reported that miR-9 directly targeted autophagy protein 5 (Atg5) and could suppress the viability of MTC cells in vitro, thus indicating an important role for miR-9 in the pathogenesis of thyroid cancer. Furthermore, the aberrant expression of the proto-oncogene BRAF has been associated with the development of PTC, and the BRAF ${ }^{\mathrm{V} 600 \mathrm{E}}$ mutation has been considered to be implicated in the progression and lymph node metastasis of PTC (26-28). Therefore, the present study aimed to explore the putative relationship between miR-9 and BRAF expression in PTC.

In the present study, the roles of miR-9 in the development and progression of PTC were investigated in vitro and in vivo. The present findings will help in the understanding of the molecular processes involved in thyroid cancer and in the development of novel therapeutic approaches for the treatment of patients with PTC.

\section{Materials and methods}

Subjects. A total of 60 pairs of fresh frozen PTC tissue samples and paired adjacent non-cancerous tissues were collected at Sichuan Provincial People's Hospital (Chengdu, China) between March 2014 and November 2015. All samples were collected from patients with PTC who had not received any previous adjuvant treatments, including chemotherapy, radiotherapy or hormone therapy. All patients were diagnosed with PTC based on histopathological evaluation. The samples were immediately stored in liquid nitrogen until further use. The present study was approved by the Ethics Committee of Sichuan Provincial People's Hospital. Written informed consent was obtained from all patients prior to enrollment in the present study. The clinicopathological characteristics of the patients are presented in Table I.

Cell culture. The human TPC-1 thyroid gland papillary carcinoma cell line was purchased from Bena Culture Collection (Beijing, China) and cultured in Dulbecco's modified Eagle's medium (Sigma-Aldrich; Merck KGaA, Darmstadt, Germany) supplemented with $10 \%$ fetal bovine serum, $100 \mathrm{U} / \mathrm{ml}$ penicillin and $100 \mu \mathrm{g} / \mathrm{ml}$ streptomycin (Invitrogen; Thermo Fisher Scientific, Inc., Waltham, MA, USA). Cells were maintained in a humidified incubator in a $5 \% \mathrm{CO}_{2}$ atmosphere at $37^{\circ} \mathrm{C}$.

Cell transfection. The miR-9 mimics, miR-9 inhibitor and scramble oligonucleotides were purchased from Shanghai GenePharma Co., Ltd. (Shanghai, China). The sequence of the miR-9 mimics was 5'-UCUUUGGUUAUCUAGCUGUA UGA-3'; the sequence of the miR-9 inhibitor was 5'-UCAUAC AGCUAGAUAACCAAAGA-3'; the sequence of the scramble oligonucleotides was 5'-CAGUACUUUUGUGUAGUACAA-3'. The overexpression vector for BRAF (pcDNA3.1-BRAF) was constructed by cloning the BRAF open reading frame sequence (range, 226-2,529, without 3'-UTR) into the multiple cloning site of the pcDNA3.1 vector (Invitrogen; Thermo Fisher Scientific, Inc.).
Table I. Association between miR-9 expression levels in PTC tissues and clinicopathological characteristics of patients with PTC.

\begin{tabular}{|c|c|c|c|c|}
\hline \multirow[b]{2}{*}{ Characteristic } & \multirow[b]{2}{*}{$\begin{array}{l}\text { Total } \\
\text { number }\end{array}$} & \multicolumn{2}{|c|}{$\begin{array}{c}\text { miR-9 } \\
\text { expression }\end{array}$} & \multirow[b]{2}{*}{ P-value } \\
\hline & & $\begin{array}{l}\text { Low } \\
(\mathrm{n}=28)\end{array}$ & $\begin{array}{l}\text { High } \\
(\mathrm{n}=32)\end{array}$ & \\
\hline \multicolumn{5}{|l|}{ Age (years) } \\
\hline$<50$ & 24 & 13 & 11 & 0.342 \\
\hline$\geq 50$ & 36 & 15 & 21 & \\
\hline \multicolumn{5}{|l|}{ Sex } \\
\hline Male & 47 & 23 & 24 & 0.503 \\
\hline Female & 13 & 5 & 8 & \\
\hline \multicolumn{5}{|l|}{$\begin{array}{l}\text { Cervical lymph } \\
\text { node metastasis }\end{array}$} \\
\hline Positive & 23 & 14 & 9 & 0.082 \\
\hline Negative & 37 & 14 & 23 & \\
\hline \multicolumn{5}{|l|}{ TNM stage } \\
\hline $\mathrm{I} / \mathrm{II}$ & 35 & 11 & 24 & 0.005 \\
\hline III/IV & 25 & 17 & 8 & \\
\hline
\end{tabular}

PTC, papillary thyroid carcinoma; TNM, tumor-lymph node-metastasis.

TPC-1 cells $\left(1 \times 10^{6}\right)$ were cultured in 6-well culture plates, and transfection was performed using Lipofectamine ${ }^{\circledR} 3000$ (Invitrogen; Thermo Fisher Scientific, Inc.) according to the manufacturer's protocol until confluence reached 50-60\%. Untransfected cells served as a control. Following $48 \mathrm{~h}$ of transfection, the cells were harvested and used for further experiments.

$R N A$ extraction and reverse transcription-quantitative polymerase chain reaction ( $R T-q P C R)$. Total RNA from tissues and cells was isolated using TRIzol reagent (Invitrogen) according to the manufacturer's protocol. For miR-9 detection, cDNA was synthesized from total RNA using a One Step Prime script miRNA cDNA Synthesis kit (Qiagen, Inc., Valencia, CA, USA). The relative expression levels of miR-9 were detected using the mirVana ${ }^{\mathrm{TM}}$ qRT-PCR miRNA Detection kit (Invitrogen) on a preheated 7500 Real Time PCR system (Applied Biosystems; Thermo Fisher Scientific, Inc.). For BRAF mRNA detection, cDNA was synthesized from total RNA using a PrimeScript RT reagent kit (Takara Biotechnology Co., Ltd., Dalian, China). qPCR was performed for BRAF mRNA detection using the SYBR Premix Ex TaqII PCR kit (Takara Biotechnology Co., Ltd.). The relative expression levels of miR-9 were normalized to U6, whereas BRAF mRNA expression was normalized to $\beta$-actin. The data were analyzed according to the $2^{-\Delta \Delta \mathrm{Cq}}$ method (29). The PCR cycling parameters were as follows: 5 min denaturation at $95^{\circ} \mathrm{C}$; then 30 cycles of $95^{\circ} \mathrm{C}$ for $15 \mathrm{sec}, 55^{\circ} \mathrm{C}$ for $20 \mathrm{sec}, 70^{\circ} \mathrm{C}$ for $30 \mathrm{sec}$; 5 min extension at $70^{\circ} \mathrm{C}$. The primers for miR-9 (30) were designed by Applied Biosystems (Thermo Fisher Scientific, Inc.). The remaining primers were as follows: BRAF forward, 
5'-ACCACCCAATACACAGGAA-3' and reverse, 5'-CAT TGGGAGCTGATGAGGAT-3'; U6 forward, 5'-CGCTTC GGCAGCACATATACTAAAATTGGAAC-3' and reverse, 5'-GCTTCACGA ATTTGCGTGTCATCCTTGC-3'; and $\beta$-actin forward, 5'-AAACTGGAACGGTGAAGGTG-3' and reverse, 5'-AGAGAAGTGGGGTGGCTTTT-3'.

Protein isolation and western blot analysis. Cells were lysed using radioimmunoprecipitation assay lysis buffer containing protease inhibitor cocktail (Beyotime Institute of Biotechnology, Haimen, China). Protein concentration was determined using a bicinchoninic acid protein assay kit (Thermo Fisher Scientific, Inc.). Extracted protein samples $(\sim 30 \mu \mathrm{g})$ were separated by $10 \%$ SDS-PAGE and transferred onto nitrocellulose membranes (Bio-Rad Laboratories, Hercules, CA, USA). The membranes were blocked in TBS containing $0.1 \%$ Tween-20 (TBST) with 5\% skimmed milk for $1 \mathrm{~h}$ at room temperature, and were then incubated with primary antibodies against BRAF (TA890103; 1:800; OriGene Technologies, Inc., Beijing, China) at $4^{\circ} \mathrm{C}$ overnight. Following washing, the membranes were incubated with horseradish peroxidase-conjugated secondary antibodies (TA130023; 1:2,000; OriGene Technologies, Inc.). $\beta$-actin was used as the endogenous control (4970; 1:1,000 dilution; Cell Signaling Technology, Inc., Danvers, MA, USA). Protein bands were visualized using the enhanced chemiluminescence (ECL) kit (Thermo Fisher Scientific, Inc.), and blots were semi-quantified using Image J software version 1.46 (National Institutes of Health, Bethesda, MD, USA).

Luciferase reporter assay. Bioinformatics analysis was performed to predict potential target genes for miR-9 using Targetscan (31) and miRanda (32). The results indicated that miR-9 may directly interact with the 3'-untranslated region (UTR) of the BRAF mRNA. To investigate the interaction in vitro, the 3'-UTR of BRAF containing the putative binding site for miR-9 was cloned downstream of the Renilla luciferase gene on a psiCHECK-2 reporter plasmid (Promega Corporation, Madison, WI, USA). BRAF 3'-UTR mutants were generated using the GeneTailor Site-Directed Mutagenesis system (Invitrogen; Thermo Fisher Scientific, Inc.) and were also ligated with the psiCHECK-2 vector. The constructed luciferase vectors $(0.2 \mu \mathrm{g})$ were co-transfected with miR-9 mimics, miR-9 inhibitor or scramble oligonucleotides $(100 \mathrm{nM})$ into TPC-1 cells using Lipofectamine ${ }^{\circledR} 3000$ (Invitrogen; Thermo Fisher Scientific, Inc.). The luciferase activities following $48 \mathrm{~h}$ of transfection were measured by the Dual Luciferase Reporter assay system (Promega Corporation).

Cellular apoptosis analysis. To assess cellular apoptosis, TPC-1 cells were seeded into 6-well plates at a density of $1 \times 10^{5}$ cells/well. After $48 \mathrm{~h}$, the cells were harvested and the apoptotic rates were determined using an Annexin V-fluorescein isothiocyanate/propidium iodide Apoptosis Detection kit (BD Biosciences, San Jose, CA, USA) according to the manufacturer's protocol. Cells were analyzed and the apoptotic rate was quantified using a FACScan flow cytometer (BD Biosciences).

Cellular viability analysis. Cell viability was measured using an MTT assay. TPC-1 cells were seeded in 96 well plates at a density of $5 \times 10^{3}$ cells/well. Following incubation for $24 \mathrm{~h}$ at $37^{\circ} \mathrm{C}$, the MTT Cell Proliferation and Cytotoxicity Assay kit (Beyotime Institute of Biotechnology) was used, and $40 \mu \mathrm{l}$ MTT stock solution was added to each well for $4 \mathrm{~h}$. The supernatants were discarded and $200 \mu 1$ DMSO (Sigma-Aldrich; Merck $\mathrm{KGaA}$ ) was added to dissolve the formazan crystals. The absorbance of each sample was measured at $570 \mathrm{~nm}$ using a microplate reader.

In vivo tumorigenesis. Male BALB/c athymic mice $(\mathrm{n}=30$; age, 4-6 weeks; weight, 20-22 g), purchased from Shanghai SLAC Laboratory Animal Co., Ltd. (Shanghai, China), were housed in micro-isolator cages $\left(22-25^{\circ} \mathrm{C}, 50-60 \%\right.$ humidity, 12-h light/dark cycle) with free access to food and water. TPC- 1 cells $\left(2 \times 10^{6}\right.$ cells in $100 \mu 1$ PBS $)$ were subcutaneously inoculated into the right flank of the mice. Then the mice were randomized into 5 groups ( $\mathrm{n}=6$ mice/group), and miR-9 mimics, miR-9 inhibitor, pcDNA3.1-BRAF, or scramble oligonucleotides (100 $\mathrm{nM}$ in $100 \mu$ 1 PBS) were injected into the tumors directly twice a week. The mice in the control group received vehicle (DMSO) injections. Tumor volumes were measured every 4 days using a caliper according to the following formula: Volume $=$ length $\mathrm{x} \mathrm{width}^{2} / 2$. Mice were sacrificed 4 weeks after the initial injection, and tumors were dissected. All protocols of animal experiments were approved by the Animal Ethics Committee of Sichuan Provincial People's Hospital (Sichuan, China).

Statistical analysis. All statistical analyses were performed using SPSS software version 17.0 (SPSS, Inc., Chicago, IL, USA) and GraphPad Prism software 6.0 (GraphPad Software, Inc., La Jolla, CA, USA). The statistical significance of the differences between two groups was assessed using two-tailed unpaired Student's t-test. Categorical data was compared using the Chi-square test. Data were presented as the mean \pm standard deviation from at least three independent experiments. $\mathrm{P}<0.05$ was considered to indicate a statistically significant difference.

\section{Results}

miR-9 expression is downregulated in PTC tissues. The relative expression levels of miR-9 and BRAF mRNA in PTC tissues and paired adjacent non-cancerous tissues were assessed using RT-qPCR. The relative expression levels of miR-9 in PTC tissues were significantly downregulated compared with in paired non-cancerous tissues (Fig. 1A). In addition, the mRNA expression levels of BRAF were significantly upregulated in PTC tissues compared with normal tissue samples (Fig. 1B). As presented in Table I, the downregulation of miR-9 expression was significantly associated with the advanced TNM stage $(\mathrm{P}=0.005)$, whereas no significant correlation was found between miR-9 expression and age $(\mathrm{P}=0.342)$, sex $(\mathrm{P}=0.503)$ or cervical lymph node metastasis $(\mathrm{P}=0.082)$.

BRAF expression is suppressed by miR-9 in TPC-1 cells. In the present study, human TPC-1 thyroid gland papillary carcinoma cells were transfected with miR-9 mimics or miR-9 inhibitor and the mRNA and protein expression levels of BRAF were then detected. The results of RT-qPCR demonstrated that 

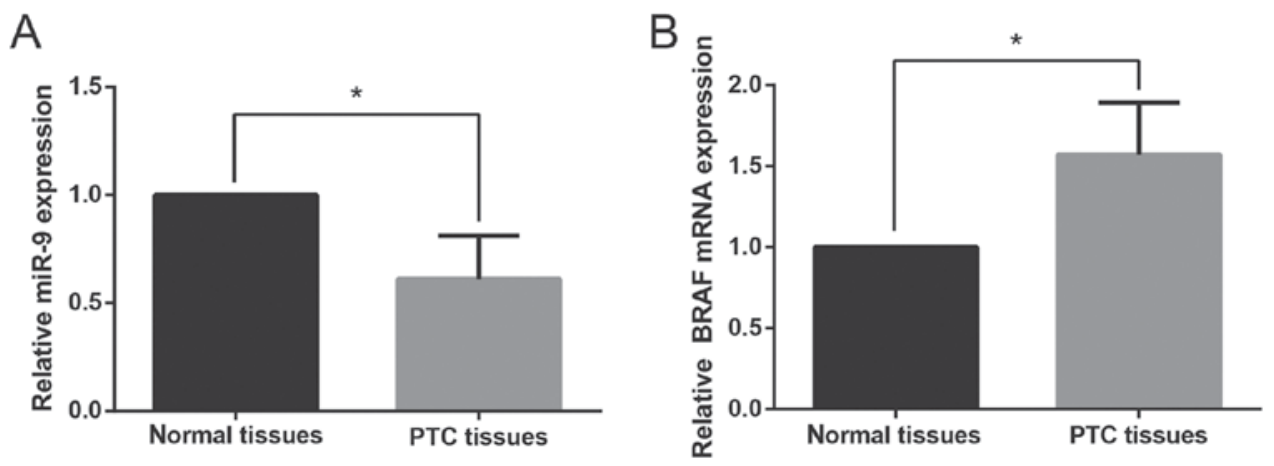

Figure 1. miR-9 and BRAF mRNA expression was assessed in PTC tissues using reverse transcription-quantitative polymerase chain reaction. (A) miR-9 expression levels in PTC tissues and paired adjacent non-cancerous tissues. (B) BRAF mRNA expression levels in PTC tissues and paired adjacent non-cancerous tissues. Data are expressed as the mean \pm standard deviation from 3 independent experiments. ${ }^{*} \mathrm{P}<0.05$, as indicated. PTC, papillary thyroid carcinoma.
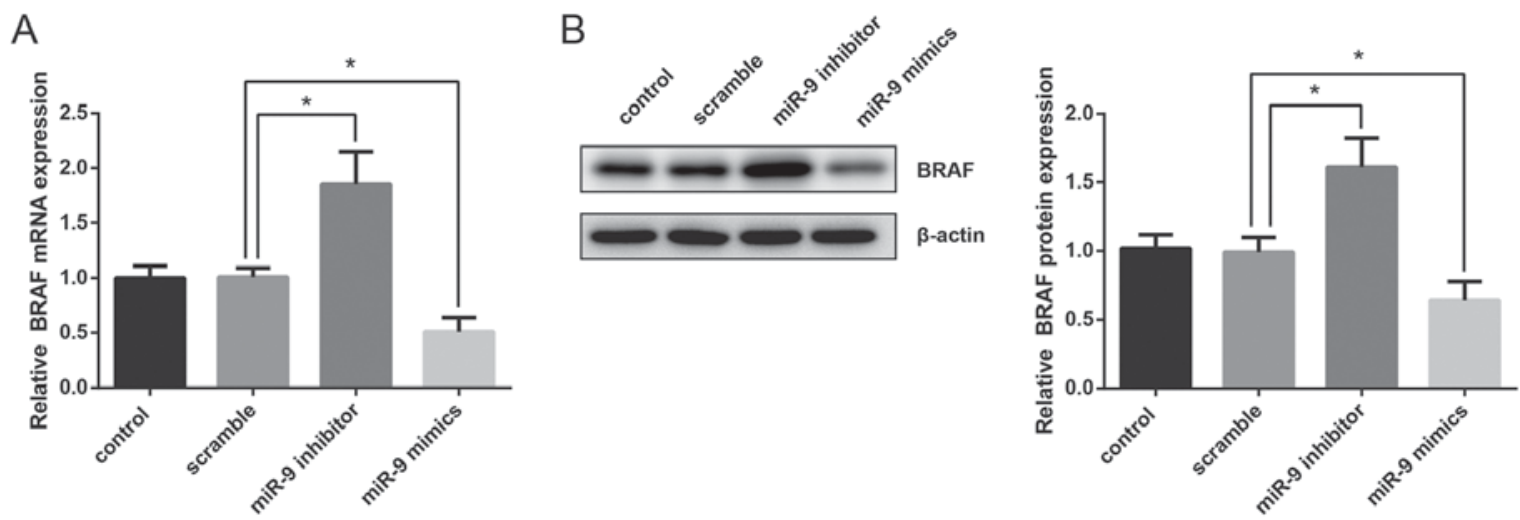

Figure 2. mRNA and protein expression levels of BRAF in human TPC-1 thyroid gland papillary carcinoma cells. (A) BRAF mRNA expression in TPC-1 cells was assessed using reverse transcription-quantitative polymerase chain reaction. (B) BRAF protein expression in TPC-1 cells was detected using western blot analysis. Data are expressed as the mean \pm standard deviation from 3 independent experiments. ${ }^{*} \mathrm{P}<0.05$, as indicated.

overexpression of miR-9 significantly suppressed the mRNA expression of BRAF, whereas inhibition of miR-9 resulted in a significant upregulation in BRAF mRNA levels (Fig. 2A). Western blot analysis also revealed that the protein expression levels of BRAF were significantly decreased following miR-9 overexpression, whereas they were increased following miR-9 inhibition (Fig. 2B).

BRAF is a direct target gene of miR-9 in TSC-1 cells. Bioinformatics analysis identified a potential binding site for miR-9 in the 3'-UTR of the BRAF mRNA (Fig. 3A). A luciferase reporter assay was performed to confirm the putative interaction in vitro. As presented in Fig. 3B, the luciferase activity in TSC-1 cells transfected with a luciferase vector encoding the wild-type BRAF 3'-UTR was significantly suppressed following transfection with miR-9 mimics. Conversely, TSC-1 cells transfected with the mutated BRAF 3'-UTR sequence were not markedly affected by miR-9 mimics or inhibitor, indicating that miR-9 may directly target BRAF expression in TSC-1 cells (Fig. 3B).

miR-9 inhibits the proliferation and promotes the apoptosis of TSC-1 cells. Flow cytometric analysis was performed to evaluate the effects of miR-9 on cancer cell apoptosis. The apoptotic rates of TSC-1 cells were significantly elevated following transfection with miR-9 mimics. By contrast, co-transfection with pcDNA3.1-BRAFsuppressed theincrease ofapoptoticrates.These

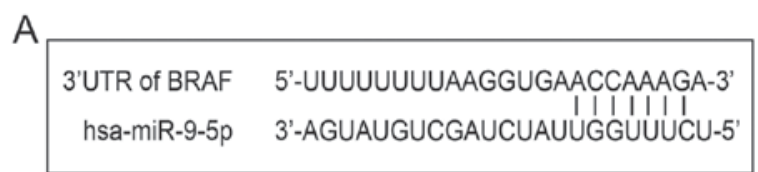

B

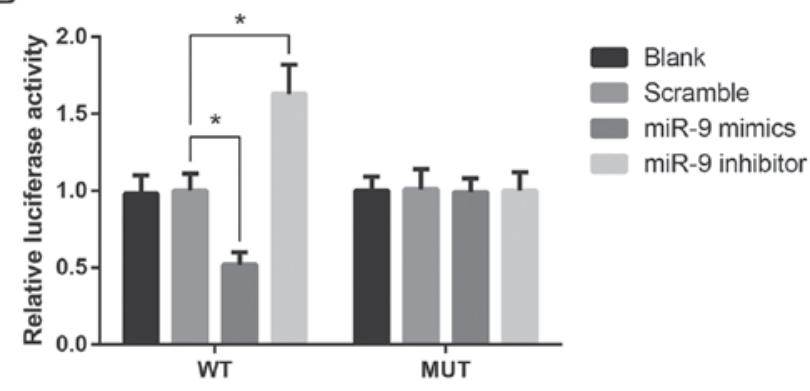

Figure 3. BRAF is a direct target gene of miR-9. (A) Bioinformatics analysis predicted a potential miR-9 binding site on the BRAF 3'-UTR. (B) Relative luciferase activities were detected in human TPC-1 thyroid gland papillary carcinoma cells transfected with WT or MUT BRAF 3'-UTR reporter constructs. Data are expressed as the mean \pm standard deviation from 3 independent experiments. " $\mathrm{P}<0.05$, as indicated. UTR, untranslated region; WT, wild-type; MUT, mutant.

findings suggested that miR-9 may be involved in the regulation of PTC cell apoptosis, through the modulation of BRAF expression (Fig. 4). 

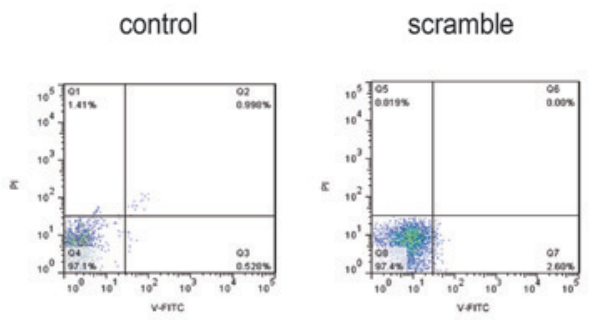

miR-9 mimics

miR-9 inhibitor
miR-9 mimics + pcDNA3.1-BRAF
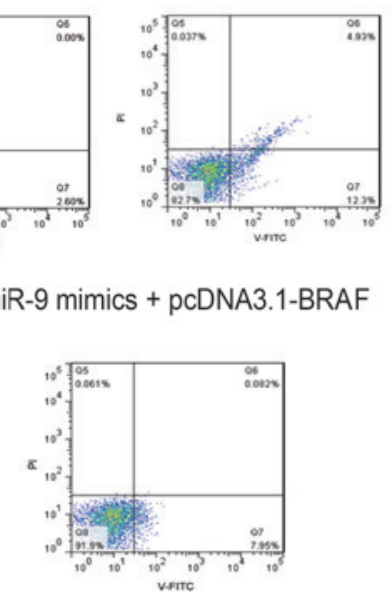

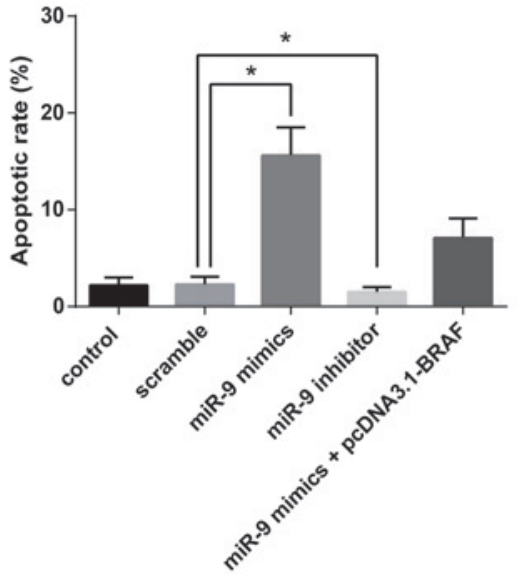

Figure 4. miR-9 is implicated in the regulation of human TPC-1 thyroid gland papillary carcinoma cell apoptosis in vitro. Cell apoptosis was detected using flow cytometry. Data are expressed as the mean \pm standard deviation from 3 independent experiments. ${ }^{*} \mathrm{P}<0.05$, as indicated. FITC, fluorescein isothiocyanate; PI, propidium iodide.

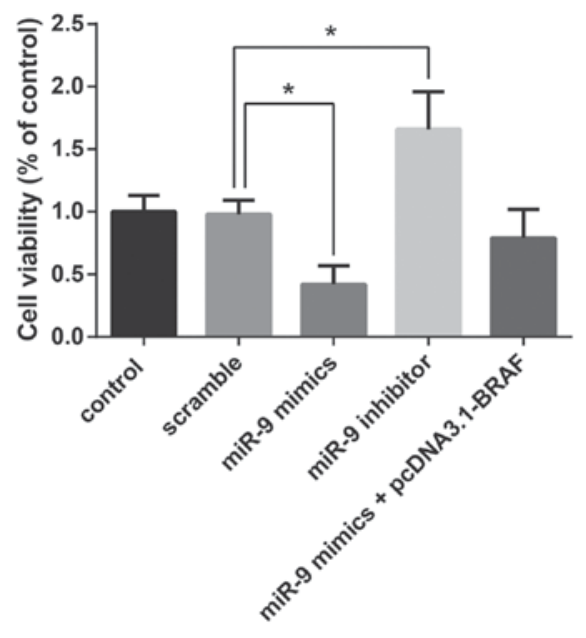

Figure 5. miR-9 is implicated in the regulation of human TPC-1 thyroid gland papillary carcinoma cell viability in vitro. Cell viability was measured using an MTT assay. Data are expressed as the mean \pm standard deviation from 3 independent experiments. ${ }^{*} \mathrm{P}<0.05$, as indicated.

MTT assay demonstrated that overexpression of miR-9 resulted in the significant suppression of TPC-1 cell proliferation, whereas co-transfection with pcDNA3.1-BRAF restored the miR-9-induced inhibition of cell viability (Fig. 5).

miR-9 suppresses in vivo PTC tumorigenesis in xenografted mice. As shown in Fig. 6, tumor growth in mice treated with the miR-9 inhibitor was significantly increased compared with the control or scramble-treated mice. Notably, miR-9 overexpression significantly suppressed tumor growth in vivo, whereas this effect was restored following the co-administration of pcDNA3.1-BRAF (Fig. 6). These results indicated that miR-9/BRAF may be implicated in the regulation of in vivo PTC tumorigenesis.

\section{Discussion}

PTC is one of the most common types of thyroid cancer, and its incidence rate has increased by $>240 \%$, with $\sim 62,980$ expected new cases in 2014, thus making PTC a major issue for human health worldwide (33). Currently, miRNAs have been suggested as potential prognostic and diagnostic biomarkers in various types of human cancer. Previous studies have demonstrated that dysregulation of the expression of several miRNAs was involved in the pathogenesis of thyroid cancer (34-36). The recurrence of PTC still remains high following thyroidectomy, thus stressing the need for the elucidation of the exact molecular mechanisms implicated in PTC pathogenesis.

The results of the present study demonstrated that miR-9 was significantly downregulated in PTC tissues compared with adjacent non-cancerous tissue samples. In addition, luciferase activity assay revealed that miR-9 directly targeted BRAF and suppressed its expression, thereby suppressing the viability and enhancing the apoptosis of human TSC-1 thyroid gland papillary carcinoma cells. Furthermore, the results of a mouse thyroid tumor xenograft model suggested that miR-9 may suppress tumor growth in vivo.

The present results demonstrating the suppression of miR-9 expression in PTC tissues were consistent with previous studies $(20,24)$ investigating the roles of miR-9 in thyroid cancer. Gundara et al (25) reported that miR-9 inhibited the autophagic flux and increased the apoptosis of cancer cells in MTC; autophagy has been suggested as one of the survival mechanisms in MTC cells. However, the association between miR-9 and autophagy has yet to be further explored.

In recent years, studies of signal transduction pathways have made a great contribution to the understanding of the molecular mechanisms implicated in tumorigenesis. At present, four mitogen-activated protein kinase (MAPK) signal transduction pathways have been identified in eukaryotic cells, including the extracellular signal-regulated kinase (ERK) pathway, the c-Jun N-terminal kinase/stress activated protein kinase pathway, the p38 pathway and the ERK5 pathway. The MAPK pathway, which includes the kinases Ras, Raf, MAPK/ERK kinase (MEK) and ERK, is implicated in the regulation of several cellular processes, including proliferation, differentiation, apoptosis and survival (37). In patients with PTC, $~ 80 \%$ of gain-of-function mutations have 

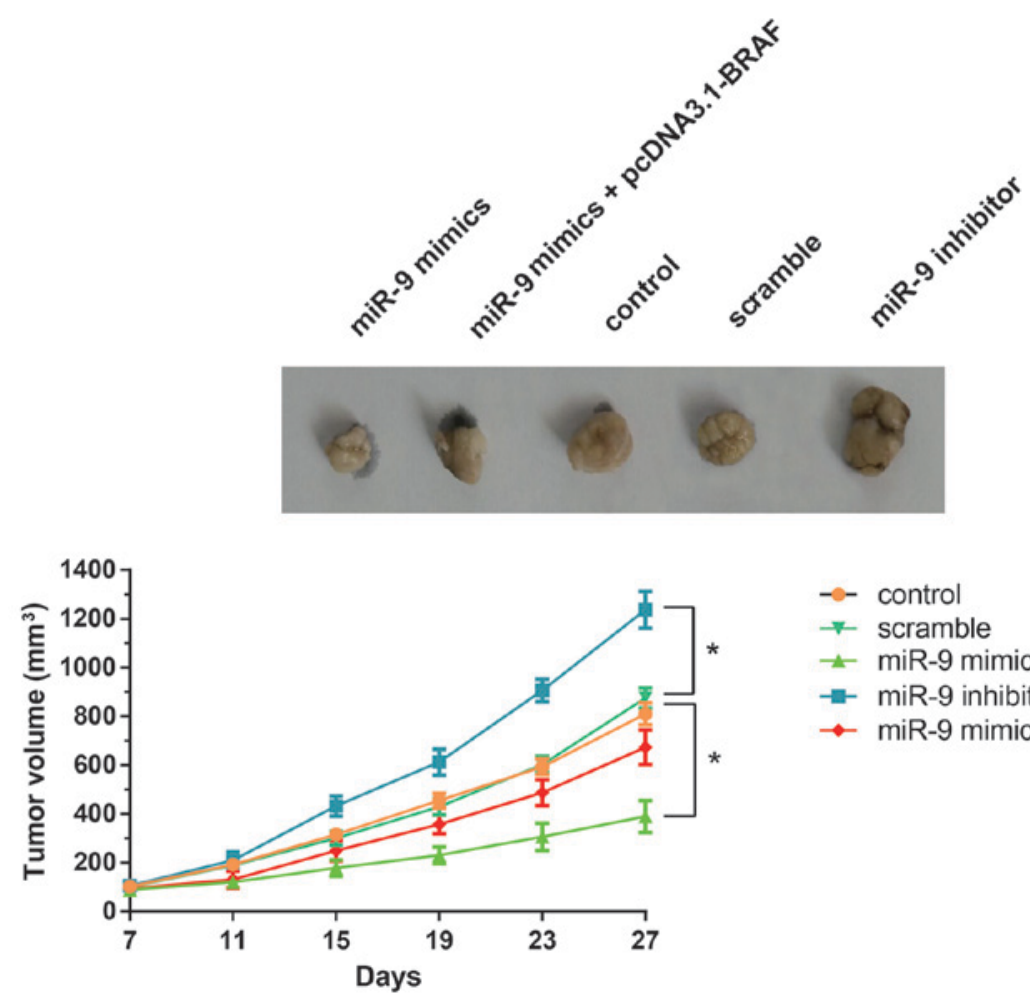

$-\infty$ control

$\rightarrow$ scramble

$₫$ miR-9 mimics

$\Rightarrow$ miR-9 inhibitor

$\rightarrow$ miR-9 mimics + pcDNA3.1-BRAF

Figure 6. miR-9 overexpression suppresses in vivo papillary thyroid carcinoma tumorigenesis in a mouse thyroid tumor xenograft model. Tumor volumes were measured every 4 days after the initial inoculation ( $\mathrm{n}=6$ mice/group). Representative tumors are included. Data are expressed as the mean \pm standard deviation from 3 independent experiments. $\mathrm{P}<0.05$, as indicated.

been identified in genes encoding signaling molecules participating in the MAPK pathways, thus suggesting that MAPK pathways may serve a critical role in the pathogenesis of PTC (38). Zawistowski et al (39) reported that miR-9 inhibited the $\mathrm{MEK} / \mathrm{ERK}$ signaling pathway via targeting integrin $\beta-1$ in breast cancer. However, the exact molecular mechanisms underlying the involvement of miR-9 in the development of PTC have yet to be elucidated. To the best of our knowledge, the present study is the first to demonstrate that miR-9 could directly target BRAF to suppress the proliferation and growth of thyroid cancer cells in vitro.

BRAF is implicated in the activation of the MAPK pathway and belongs to the Raf family of kinases. BRAF is a critical factor participating in the pathogenesis of thyroid cancer, and a high frequency of BRAF mutations has been detected among patients with PTC (40). Accumulating evidence suggests that a mutation in BRAF at the amino acid residue 600 (V600E) may be associated with the prognosis of patients with PTC (41-43). BRAF may be implicated in PTC progression through several signaling pathways, including the MEK/ERK and the phosphatidylinositol-4,5-bisphosphate 3-kinase/Akt pathway (44-46). Notably, Zhang et al (47) demonstrated that inhibition of miR-9 reversed the effects of BRAF-activated non-coding RNA on gastric cancer cell growth and apoptosis, via targeting nuclear factor- $\kappa \mathrm{B} 1$.

The results of the present study suggested that miR-9 may suppress the activation of the MEK/ERK signaling pathway via binding to the 3'-UTR of BRAF and suppressing its expression; low expression levels of BRAF may inhibit the activation of MEK/ERK signaling. Inhibition of the MEK/ERK pathway using synthetic pharmacological agents has been demonstrated to inhibit the progression of various types of cancer (48). In addition, BRAF has been associated with cancer development and it may serve an important role in signal transduction through the phosphorylation of MEK1/2 and ERK1/2 (49).

In conclusion, the present study revealed that miR-9 expression was downregulated in PTC tissues, whereas miR-9 overexpression inhibited BRAF expression, suppressed PTC cell proliferation and promoted PTC cell apoptosis. Further studies are required to investigate the molecular mechanisms underlying the pathogenesis of PTC, and identify novel therapeutic approaches for the treatment of patients with PTC.

\section{Acknowledgements}

Not applicable.

\section{Funding}

No funding was received.

\section{Availability of data and materials}

The datasets used and/or analyzed during the current study are available from the corresponding author on reasonable request.

\section{Authors' contributions}

YG designed the research, analyzed data and wrote the manuscript. NY, LY, CF and TL performed the research and analyzed data. All authors read and approved the final manuscript. 


\section{Ethics approval and consent to participate}

The present study was approved by the Ethics Committee of Sichuan Provincial People's Hospital (Sichuan, China). Written informed consent was obtained from all patients prior to enrollment in the present study. All protocols of animal experiments were approved by the Animal Ethics Committee of Sichuan Provincial People's Hospital.

\section{Consent for publication}

Written informed consent was obtained from all patients prior to enrollment in the present study.

\section{Competing interests}

The authors declare that they have no competing interests.

\section{References}

1. Pacini F: Thyroid microcarcinoma. Best Pract Res Clin Endocrinol Metab 26: 381-389, 2012.

2. Pellegriti G, Frasca F, Regalbuto C, Squatrito $S$ and Vigneri R: Worldwide increasing incidence of thyroid cancer: Update on epidemiology and risk factors. J Cancer Epidemiol 2013: 965212 , 2013.

3. Hanley JP, Jackson E, Morrissey LA, Rizzo DM, Sprague BL, Sarkar IN and Carr FE: Geospatial and temporal analysis of thyroid cancer incidence in a rural population. Thyroid 25: 812-822, 2015

4. Magreni A, Bann DV, Schubart JR and Goldenberg D: The effects of race and ethnicity on thyroid cancer incidence. JAMA Otolaryngol Head Neck Surg 141: 319-323, 2015.

5. Zolotov S: Genetic testing in differentiated thyroid carcinoma: Indications and clinical implications. Rambam Maimonides Med J 7: 28 Jan 2016 doi: 10.5041/RMMJ.10236.

6. Griniatsos J, Tsigris C, Kanakis M, Kaltsas G, Michail O, Dimitriou N, Argyrakopoulou G, Delladetsima I, Kyriakou V, Syriou V, et al: Increased incidence of papillary thyroid cancer detection among thyroidectomies in Greece between 1991 and 2006. Anticancer Res 29: 5163-5169, 2009.

7. Hakala T, Kellokumpu-Lehtinen P, Kholová I, Holli K, Huhtala H and Sand J: Rising incidence of small size papillary thyroid cancers with no change in disease-specific survival in finnish thyroid cancer patients. Scand J Surg 101: 301-306, 2012.

8. Kuo EJ, Goffredo P, Sosa JA and Roman SA: Aggressive variants of papillary thyroid microcarcinoma are associated with extrathyroidal spread and lymph-node metastases: A population-level analysis. Thyroid 23: 1305-1311, 2013

9. Ghossein R, Ganly I, Biagini A, Robenshtok E, Rivera M and Tuttle RM: Prognostic factors in papillary microcarcinoma with emphasis on histologic subtyping: A clinicopathologic study of 148 cases. Thyroid 24: 245-253, 2014.

10. Grant CS: Recurrence of papillary thyroid cancer after optimized surgery. Gland Surg 4: 52-62, 2015.

11. Byeon HK, Ban MJ, Lee JM, Ha JG, Kim ES, Koh YW and Choi EC: Robot-assisted Sistrunk's operation, total thyroidectomy, and neck dissection via a transaxillary and retroauricular (TARA) approach in papillary carcinoma arising in thyroglossal duct cyst and thyroid gland. Ann Surg Oncol 19: 4259-4261, 2012.

12. Lang BH, Ng SH, Lau LL, Cowling BJ, Wong KP and Wan KY: A systematic review and meta-analysis of prophylactic central neck dissection on short-term locoregional recurrence in papillary thyroid carcinoma after total thyroidectomy. Thyroid 23: 1087-1098, 2013.

13. Macedo FI and Mittal VK: Total thyroidectomy versus lobectomy as initial operation for small unilateral papillary thyroid carcinoma: A meta-analysis. Surg Oncol 24: 117-122, 2015.

14. Matsuzu K, Sugino K, Masudo K, Nagahama M, Kitagawa W, Shibuya H, Ohkuwa K, Uruno T, Suzuki A, Magoshi S, et al: Thyroid lobectomy for papillary thyroid cancer: Long-term follow-up study of 1,088 cases. World J Surg 38: 68-79, 2014.

15. He Y,Lin J, Kong D, Huang M, Xu C, Kim TK, Etheridge A, Luo Y, Ding $\mathrm{Y}$ and Wang K: Current state of circulating MicroRNAs as cancer biomarkers. Clin Chem 61: 1138-1155, 2015.
16. Zhou X, Du YL, Jin P and Ma F: Bioinformatic analysis of cancer-related microRNAs and their target genes. Yi Chuan 37: 855-864, 2015.

17. Yoruker EE, Terzioglu D, Teksoz S, Uslu FE, Gezer U and Dalay N: MicroRNA expression profiles in papillary thyroid carcinoma, benign thyroid nodules and healthy Controls. J Cancer 7: 803-809, 2016.

18. Damanakis AI,Eckhardt S, Wunderlich A, Roth S, Wissniowski TT, Bartsch DK and Di Fazio P: MicroRNAs let7 expression in thyroid cancer: Correlation with their deputed targets HMGA2 and SLC5A5. J Cancer Res Clin Oncol 142: 1213-1220, 2016.

19. Czajka AA, Wójcicka A, Kubiak A, Kotlarek M, BakułaZalewska E, Koperski Ł, Wiechno W and Jażdżewski K: Family of microRNA-146 regulates RAR $\beta$ in papillary thyroid carcinoma. PLoS One 11: e0151968, 2016.

20. Cong D, He M, Chen S, Liu X and Sun H: Expression profiles of pivotal microRNAs and targets in thyroid papillary carcinoma: An analysis of the cancer genome atlas. Onco Targets Ther 8: 2271-2277, 2015.

21. Lima CR, Geraldo MV, Fuziwara CS, Kimura ET and Santos MF: MiRNA-146b-5p upregulates migration and invasion of different papillary thyroid carcinoma cells. BMC Cancer 16: 108, 2016.

22. Minna E, Romeo P, Dugo M, De Cecco L, Todoerti K, Pilotti S, Perrone F, Seregni E, Agnelli L, Neri A, et al: miR-451a is underexpressed and targets AKT/mTOR pathway in papillary thyroid carcinoma. Oncotarget 7: 12731-12747, 2016.

23. Salajegheh A, Vosgha H, Md Rahman A, Amin M, Smith RA and Lam AK: Modulatory role of miR-205 in angiogenesis and progression of thyroid cancer. J Mol Endocrinol 55: 183-196, 2015.

24. Sondermann A, Andreghetto FM, Moulatlet AC, da Silva Victor E, de Castro MG, Nunes FD, Brandão LG and Severino P: MiR-9 and miR-21 as prognostic biomarkers for recurrence in papillary thyroid cancer. Clin Exp Metastasis 32: 521-530, 2015.

25. Gundara JS, Zhao J, Gill AJ, Lee JC, Delbridge L, Robinson BG, McLean C, Serpell J and Sidhu SB: Noncoding RNA blockade of autophagy is therapeutic in medullary thyroid cancer. Cancer Med 4: 174-182, 2015.

26. Ma B, Shi R, Yang S, Zhou L, Qu N, Liao T, Wang Y, Wang Y and Ji Q: DUSP4/MKP2 overexpression is associated with BRAF(V600E) mutation and aggressive behavior of papillary thyroid cancer. Onco Targets Ther 9: 2255-2263, 2016.

27. Gao Q, Zhang W, Wang N, Duan H, Zhou Y, Zhang W and Zhao D: Study on the correlation between BRAF(V600E) mutation and lymphatic metastases in papillary thyroid cancer staged preoperativelv as N0. Lin Chung Er Bi Yan Hou Tou Jing Wai Ke Za Zhi 29: 2048-2052, 2015 (In Chinese).

28. Cordioli MI, Moraes L, Carvalheira G, Sisdelli L, Alves MT, Delcelo R, Monte O, Longui CA, Cury AN and Cerutti JM: AGK-BRAF gene fusion is a recurrent event in sporadic pediatric thyroid carcinoma. Cancer Med 5: 1535-1541, 2016.

29. Livak KJ and Schmittgen TD: Analysis of relative gene expression data using real-time quantitative PCR and the 2(-Delta Delta C(T)) method. Methods 25: 402-408, 2001.

30. Zhuang G, Wu X, Jiang Z, Kasman I, Yao J, Guan Y, Oeh J, Modrusan Z, Bais C, Sampath D and Ferrara N: Tumour-secreted miR-9 promotes endothelial cell migration and angiogenesis by activating the JAK-STAT pathway. EMBO J 31: 3513-3523, 2012.

31. Agarwal V, Bell GW, Nam JW and Bartel DP: Predicting effective microRNA target sites in mammalian mRNAs. Elife 4: 12 Aug 2015 doi: 10.7554/eLife.05005.

32. John B, Enright AJ, Aravin A, Tuschl T, Sander C and Marks DS: Human MicroRNA targets. PLoS Biol 2: e363, 2004.

33. Conzo G, Tartaglia E, Avenia N, Calò PG, de Bellis A, Esposito K, Gambardella C, Iorio S, Pasquali D, Santini L, et al: Role of prophylactic central compartment lymph node dissection in clinically NO differentiated thyroid cancer patients: Analysis of risk factors and review of modern trends. World J Surg Oncol 14: 149, 2016.

34. Chruścik A and Lam AK: Clinical pathological impacts of microRNAs in papillary thyroid carcinoma: A crucial review. Exp Mol Pathol 99: 393-398, 2015.

35. Min XS, Huang P, Liu X, Dong C, Jiang XL, Yuan ZT, Mao LF and Chang S: Bioinformatics analyses of significant prognostic risk markers for thyroid papillary carcinoma. Tumour Biol 36: 7457-7463, 2015.

36. Forte S, La Rosa C, Pecce V, Rosignolo F and Memeo L: The role of microRNAs in thyroid carcinomas. Anticancer Res 35: 2037-2047, 2015. 
37. Roberts PJ and Der CJ: Targeting the Raf-MEK-ERK mitogenactivated protein kinase cascade for the treatment of cancer. Oncogene 26: 3291-3310, 2007.

38. Schlumberger $M$ and Sherman SI: Approach to the patient with advanced differentiated thyroid cancer. Eur J Endocrinol 166: 5-11, 2012.

39. Zawistowski JS, Nakamura K, Parker JS, Granger DA, Golitz BT and Johnson GL: MicroRNA 9-3p targets $\beta 1$ integrin to sensitize claudin-low breast cancer cells to MEK inhibition. Mol Cell Biol 33: 2260-2274, 2013

40. Ito T, Seyama T, Hayashi Y, Dohi K and Akiyama M: Unique association of p53 mutations with undifferentiated carcinoma of the thyroid. Nihon Rinsho 52: 1069-1074, 1994 (In Japanese).

41. Falchook GS, Millward M, Hong D, Naing A, Piha-Paul S, Waguespack SG, Cabanillas ME, Sherman SI, Ma B, Curtis M, et al: BRAF inhibitor dabrafenib in patients with metastatic BRAF-mutant thyroid cancer. Thyroid 25: 71-77, 2015.

42. Rothenberg SM, McFadden DG, Palmer EL, Daniels GHand Wirth LJ: Redifferentiation of iodine-refractory BRAF V600Emutant metastatic papillary thyroid cancer with dabrafenib. Clin Cancer Res 21: 1028-1035, 2015.

43. Fnais N, Soobiah C, Al-Qahtani K, Hamid JS, Perrier L, Straus SE and Tricco AC: Diagnostic value of fine needle aspiration $\mathrm{BRAF}(\mathrm{V} 600 \mathrm{E})$ mutation analysis in papillary thyroid cancer: A systematic review and meta-analysis. Hum Pathol 46 $1443-1454,2015$.
44. Yi W, Zhong D and Zou Q: Expression of BRAF and its extracellular signal-regulated kinase $1 / 2$ signal pathway in papillary thyroid cancer. Zhong Nan Da Xue Xue Bao Yi Xue Ban 37: 889-894, 2012 (In Chinese).

45. Kandil E, Tsumagari K, Ma J, Abd Elmageed ZY, Li X, Slakey D, Mondal D and Abdel-Mageed AB: Synergistic inhibition of thyroid cancer by suppressing MAPK/PI3K/AKT pathways. J Surg Res 184: 898-906, 2013

46. McCarty SK, Saji M, Zhang X, Knippler CM, Kirschner LS, Fernandez S and Ringel MD: BRAF activates and physically interacts with PAK to regulate cell motility. Endocr Relat Cancer 21: 865-877, 2014.

47. Zhang ZX, Liu ZQ, Jiang B, Lu XY, Ning XF, Yuan CT and Wang AL: BRAF activated non-coding RNA (BANCR) promoting gastric cancer cells proliferation via regulation of NF-kB1. Biochem Biophys Res Commun 465: 225-231, 2015.

48. Hu Y, Mintz A, Shah SR, Quinones-Hinojosa A and Hsu W: The FGFR/MEK/ERK/brachyury pathway is critical for chordoma cell growth and survival. Carcinogenesis 35: 1491-1499, 2014.

49. Wellbrock $C$ and Arozarena I: The Complexity of the ERK/MAP-kinase pathway and the treatment of melanoma skin cancer. Front Cell Dev Biol 4: 33, 2016. 